\title{
Stresses and anxieties in the time of the COVID-19 pandemic - what we can learn
}

\author{
Rama S. Ayyala ${ }^{1}$ (D) - George A. Taylor ${ }^{2,3} \cdot$ Michael J. Callahan $^{2}$ \\ Received: 17 April 2020 / Revised: 17 April 2020 / Accepted: 18 May 2020 / Published online: 30 May 2020 \\ (C) Springer-Verlag GmbH Germany, part of Springer Nature 2020
}

"Adversity is the mother of progress." - Mahatma Gandhi

The COVID-19 pandemic has created unprecedented complex challenges for society and has heightened our awareness of preexisting deficiencies in our health care system.

Long-standing discrepancies in access to health care and health insurance, particularly racial and income-based inequalities, have become more apparent than ever during the pandemic. Within the medical community, the arrival of COVID-19 has added yet another acute level of stress and potential cause for burnout, in addition to the previously recognized drivers of burnout and job-related stress, such as burdensome administrative requirements and electronic medical record systems as well as increasing demands for higher productivity $[1,2]$. The added stress on healthcare workers due to COVID-19 is in at least three different forms: moral injury, grief and concerns for personal safety.

\section{Moral injury}

This term was first used among combat veterans to characterize post-traumatic stress. During wartime, service members may act in ways that offend deeply held moral and ethical beliefs. They may be exposed to intense human suffering

Rama S. Ayyala

rayyala@gmail.com

1 Department of Diagnostic Imaging, Rhode Island Hospital - Hasbro Children's Hospital, Warren Alpert Medical School of Brown University, 593 Eddy St., Providence, RI 02903, USA

2 Department of Radiology, Boston Children's Hospital, Boston, MA, USA

3 Department of Radiology, Children's Hospital of Philadelphia, Philadelphia, PA, USA and cruelty that disturb their core beliefs about humanity. These events may result in lasting emotional, psychological, social, behavioral and spiritual injury [3]. Before this pandemic, a strong case had been made that a more appropriate characterization of physician burnout is moral injury among physicians, previously thought to be due to the "increasingly complex web of providers' highly conflicted allegiances — to patients, to self, and to employers" [4]. However, in the current situation, moral injury has taken on new meaning among health care workers who are fighting a war against COVID19. Clinicians and other health care workers are facing situations that were never fathomed before, such as difficult triage decisions for critically ill patients due to limitations in resources, including ventilators and other vital therapies. These issues are affecting health care workers in all medicine subspecialties in different ways, with radiologists not immune to this phenomenon. Radiologists may be experiencing moral distress due to limiting access to imaging in patients presenting with urgent or emergent conditions, effectively depriving children of nonurgent, yet needed, imaging studies. At the same time, radiologists may experience moral distress associated with not being on the front line like other clinical colleagues, such as emergency medicine and intensive care unit physicians. As health care workers, radiologists enter the field with the intention of providing the best patient care. The current times are severely testing those assumptions.

\section{Grief}

The world changed drastically in the first few months of 2020 . We lost a sense of normalcy, and now are left with a great deal of uncertainty about how long this crisis will last and what the world will look like when we emerge from the pandemic. Experts have termed this coping mechanism as anticipatory grief [5]. Many of us associate grief with a response to devastating outcomes, such as the death of a loved one. We are all witnessing and experiencing unexpected hardships and the 
loss of the sense of safety that comes with feeling in control and being able to predict expectations, both personally and professionally. There are several contributing drivers, including lower overall imaging volumes resulting in decreased revenues to many departments and institutions. The repercussions to individuals are as yet unclear, although some have already experienced pay decreases and furloughs. In addition, guidelines for social and physical distancing have decreased the number of radiologists physically present in the department, taking away the sense of purpose associated with being able to perform examinations and interact with patients. Similarly, working from remote locations leaves us unable to interact with colleagues, a large source of regular social interactions.

\section{Personal safety}

Many health care workers are being asked to assume greater risks to their personal safety and that of their families, exacerbated by a lack of personal protective equipment (PPE). Our technologists, nurses and radiologists are our frontline staff and are faced with a higher risk of exposure to the virus, especially when performing invasive procedures on highrisk patients. Outside the hospital, physical and social distancing measures have heightened awareness of personal health vulnerabilities, especially for those who are older or have underlying health issues that can increase the risk of infection. Lastly, we are all grappling with the uncertainty of the financial implications of this pandemic: How long and how severe will they be, both for departments/institutions and individuals? Will I lose my job? Will I lose my health insurance? Will I lose my housing? These questions raise concerns that few of us had considered until recently.

\section{What can we do?}

A recent article detailed sources of anxieties in health care professionals and suggested lessons to be learned and applied in moving forward after the pandemic. The authors engaged in eight listening sessions with a total of 69 physicians, nurses, advanced practice clinicians, residents and fellows during the first week of the COVID-19 pandemic. They explored three key concerns: what health care professionals were most concerned about, what messaging and behaviors they needed from their leaders, and what other tangible sources of support they believed would be most helpful to them [6].

"Hear me": More so than ever, it is especially important to listen to the concerns of those in the department and for leadership to be present and available. Different avenues for input and feedback can be created, such as email suggestion boxes and virtual town hall meetings. Radiology leaders must ensure these discussions happen not only for radiologists, but also for other members of the department (technologists, office staff, research personnel, trainees, etc.).

"Protect me": In radiology, our primary frontline health care workers typically consist of technologists and nurses, followed by radiologists and other mid-level providers. It is critically important to assure everyone's safety is being addressed in these uncertain times, particularly those on the front line. This assurance ranges from regular and frequent messaging and communication from hospital and departmental leadership, adequate PPE and updated PPE guidelines, consistent safety protocols to minimize staff viral exposure, and support for department members from financial repercussions when they are unable to carry out their duties. One potential resource for radiology departments is the Coronavirus Aid, Relief and Economic Security (CARES) loan program (https://www.acr.org/Advocacy-and-Economics/ Advocacy-News/Advocacy-News-Issues/In-the-April-4-2020Issue/CARES-Act-Offers-Loans-and-Tax-Relief-to-RadiologyPractices). Most radiology departments and medical institutions are already undergoing economic hardships and are attempting to protect their members from the effects. This is an unfortunate consequence of the pandemic and will require a coordinated effort at national, institutional and departmental levels.

"Prepare me": Some radiology staff are being repurposed to work in other areas of the hospital with more significant needs. Providing adequate training for these roles is key. Within departments, it is important to clearly communicate the challenges and decisions being made. Inconsistent messaging by leadership should be avoided whenever possible. It is also important to make clear that people should not be afraid to ask for help. Everyone is navigating new challenges and it is important for people to know they are not alone.

"Support me": Radiologists are being asked to read remotely (either in their offices or at home), which can be very isolating. In addition, the complex balancing act of dealing with other life stressors may be more apparent than ever. These include working from home with a family and tending to children, potentially overseeing homeschooling, caring for other loved ones who may be in high-risk populations (the elderly or those with underlying medical conditions), and being forced to face one's own vulnerabilities that put them at risk. It is important to support one another and acknowledge that everyone has their own unique struggles, stresses and anxieties during these times. Compassion, tolerance, understanding and support for our coworkers is more important than ever [7]. With technology and virtual portals of communication, a simple text or email check-in can make a huge difference.

"Care for me": Pediatric radiology departments vary in size and organization, therefore initiatives that work at one place may not be implemented effectively at another. For instance, small pediatric radiology departments may have challenges in staffing, especially if a radiologist or a family member is affected personally by the virus. In a larger free-standing pediatric radiology department, low examination volumes can 
impose restrictions on needed personnel, potentially putting people in financial limbo. Trainees are also experiencing unique stresses, such as fewer cases to read and learn from, as well as decreased opportunities for learning at the workstation from attending radiologists. A myriad of stresses will arise from this pandemic, and it will be different for every department and individual - unprecedented work-related stresses never previously accounted for in our assessment of work-related stress and burnout. Ultimately, the key is for all levels of the organization to support the individuals in the department.

\section{What can we take away from this time?}

None of us chose to be in our current situation. All of the concerns and stresses we are facing related to COVID-19 are undoubtedly real and justified; however, the manner by which we cope with these newfound pressures is of utmost importance so that the grief is not all-consuming. We are all sharing in the uncertainty of what will happen to us, to our families and to our communities. With it comes the important task of managing our anticipatory grief. David Kessler, grief expert, and the coauthor of On Grief and Grieving with Elizabeth Kübler-Ross, has added a sixth stage to the traditional five stages of grief (denial, anger, bargaining, depression and acceptance): meaning [5]. After accepting that we have to deal with this new reality, it is important to find lessons, positive or negative, from these difficult times. We also have an opportunity to rediscover and appreciate things we may have taken for granted. The simple act of connecting with others has allowed us to acknowledge individual vulnerability and has become heightened as one of the most powerful coping mechanisms. Focusing on these acts can help one be in the present, rather than agonizing over the uncertainty of the future. We are all dealing with different stresses and anxieties, and we all cope differently. The future is yet to be determined, but we are learning from this journey. These lessons will ultimately strengthen the pediatric radiology community, with one of the most important lessons being simply to be there for each other.

\section{Compliance with ethical standards}

Conflicts of interest None

\section{References}

1. Ayyala RS, Ahmed F, Ruzal-Shapiro CB, Taylor G (2019) Stressors contributing to burnout amongst pediatric radiologists: results from a survey of the Society for Pediatric Radiology. Pediatr Radiol 49: 714-722

2. Ayyala RS, Baird GL, Sze R et al (2020) The growing issue of burnout in radiology- a survey-based evaluation of driving factors and potential impacts in pediatric radiologists. Pediatr Radiol. https:// doi.org/10.1007/s00247-020-04693-2

3. Litz BT, Stein N, Delaney E et al (2009) Moral injury and moral repair in war veterans: a preliminary model and intervention strategy. Clin Psychol Rev 29:695-706

4. Talbot SG, Dean W (2018) Physicians aren't "burning out": They are suffering moral injury. https://www.statnews.com/2018/07/26/ physicians-not-burning-out-they-are-suffering-moral-injury/. Accessed 18 January 2019

5. Berinato $S$ (2020) That discomfort you're feeling is grief. Harv Bus Rev. https://hbr.org/2020/03/that-discomfort-youre-feeling-is-grief. Accessed 17 April 2020

6. Shanafelt T, Ripp J, Trockel M (2020) Understanding and addressing sources of anxiety among health care professionals during the COVID-19 pandemic. JAMA. https://doi.org/10.1001/jama.2020. 5893

7. Gallo A (2020) What your coworkers need right now is compassion. Harv Bus Rev. https://hbr.org/2020/03/what-your-coworkers-needright-now-is-compassion. Accessed 17 April 2020

Publisher's note Springer Nature remains neutral with regard to jurisdictional claims in published maps and institutional affiliations. 